\title{
Detailed characterization of tumor infiltrating lymphocytes in two distinct human solid malignancies show phenotypic similarities
}

Magdalena Kovacsovics-Bankowski ${ }^{1}$, Lana Chisholm¹, Jonna Vercellini ${ }^{1}$, Christopher G Tucker ${ }^{1,2}$, Ryan Montler ${ }^{2}$, Daniel Haley ${ }^{1}$, Philippa Newell ${ }^{1}$, Jun $\mathrm{Ma}^{3}$, Paul Tseng ${ }^{3}$, Ronald Wolf ${ }^{5}$, John T Vetto ${ }^{4}$, Chet Hammill ${ }^{5}$,

Paul Hansen ${ }^{5}$ and Andrew D Weinberg ${ }^{1,2^{*}}$

\begin{abstract}
Background: We examined the phenotype and function of lymphocytes collected from the peripheral blood (PBL) and tumor (TIL) of patients with two different solid malignancies: colorectal cancer liver metastases (CRLM) and ovarian cancer (OVC).

Methods: Tumor and corresponding peripheral blood were collected from 16 CRLM and 22 OVC patients; immediately following resection they were processed and analyzed using a multi-color flow cytometry panel. Cytokine mRNA from purified PBL and TIL CD4 ${ }^{+}$T cells were also analyzed by qPCR.

Results: Overall, we found similar changes in the phenotypic and cytokine profiles when the TIL were compared to PBL from patients with two different malignancies. The percentage of Treg $\left(\mathrm{CD}^{+} / \mathrm{CD} 25^{+} / \mathrm{FoxP} 3^{+}\right)$in PBL and TIL was similar: $8.1 \%$ versus $10.2 \%$, respectively in CRLM patients. However, the frequency of Treg in primary OVC TIL was higher than PBL: $19.2 \%$ versus $4.5 \%$ ( $p<0.0001$ ). A subpopulation of Treg expressing HLA-DR was markedly increased in TIL compared to PBL in both tumor types, CRLM: $69.0 \%$ versus $31.7 \%(p=0.0002)$ and OVC $74.6 \%$ versus $37.0 \%(p<0.0001)$, which suggested preferential Treg activation within the tumor. The cytokine mRNA profile showed that IL-6, a cytokine known for its immunosuppressive properties through STAT3 upregulation, was increased in TIL samples in patients with OVC and CRLM. Both TIL populations also contained a significantly higher proportion of activated CD8 ${ }^{+} \mathrm{T}$ cells (HLA-DR $/$ CD $38^{+}$) compared to PBL (CRLM: $30.2 \%$ vs $7.7 \%$, ( $p=0.0012$ ), OVC: $57.1 \%$ vs $12.0 \%$, $(p<0.0001)$ ).

Conclusion: This study demonstrates that multi-color flow cytometry of freshly digested tumor samples reveals phenotypic differences in TIL vs PBL T cell sub-populations. The TIL composition in primary and metastatic tumors from two distinct histologies were remarkably similar, showing a greater proportion of activated/suppressive Treg

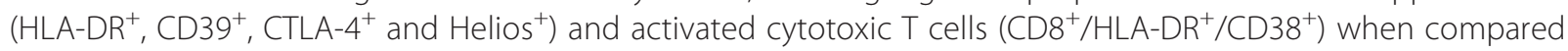
to PBL and an increase in IL-6 mRNA from CD4 TIL.
\end{abstract}

Keywords: Tumor infiltrating lymphocytes, Regulatory $T$ cells

\footnotetext{
* Correspondence: andrew.weinberg@providence.org

'Earle A. Chiles Research Institute, Providence Cancer Center, Portland

Providence Medical Center, 4805 NE Glisan St, Portland, Oregon 97213, USA

${ }^{2}$ Agonox Inc, 4805 NE Glisan St, Portland, Oregon 97213, USA

Full list of author information is available at the end of the article
} 


\section{Background}

Tumor immunotherapy has emerged as an important treatment modality for cancer patients. Historically, melanoma and renal cell carcinoma have been described as tumors that respond to immunotherapy. However, recent clinical trials have shown that a variety of other tumor types are also responding to immunotherapy [1-3].

The mechanism(s) of tumor rejection following immunotherapy treatment have been difficult to define. Until recently, most immunologic analyses in cancer patients have been conducted on PBL or tissue sections, where samples are more easily obtained. However, it is the composition of the immune cells at the tumor site that is likely to be most important; and the tumor infiltrating lymphocytes (TIL) may be quite different from the PBL. Furthermore it is extremely hard to perform immune subset analyses by immunohistochemistry. Therefore to gain a deeper understanding of how immunotherapy could potentially affect the tumor microenvironment, it would be important to first characterize the subset distribution and phenotype of the immune cells in progressively growing tumors.

The purpose of this study was to compare the phenotype and function of freshly isolated TIL to PBL in patients with progressively growing tumors by flow cytometry. Several studies, using primarily immunohistochemistry, have shown that greater frequencies of Treg cells within the tumor environment leads to a decrease in patient survival $[4,5]$. Increased Treg inhibitory function has been associated with increases in several surface and/or intra-cellular markers. Treg cells with the greatest suppressive capacity express high levels of HLA-DR and CD39 on their surface and a decline in this population has been associated with renal graft rejection or premature delivery [6,7]. In contrast to Treg frequency and phenotype, increased levels of $\mathrm{CD}^{+} \mathrm{T}$ cells in TIL has been associated with a positive clinical outcome in patients with CRC [4]. However, these studies did not examine the activation status of $\mathrm{CD}^{+} \mathrm{T}$ cells. We have used the co-expression of HLA-DR and CD38 as well as the proliferation marker Ki-67 to determine the activation status of $\mathrm{CD}^{+} \mathrm{T}$ cells isolated from TIL vs blood.

In this study, we analyzed fresh tumor and paired peripheral blood samples from patients with CRC and OVC; we compared the function and phenotype of lymphocytes from TIL to those in peripheral blood. The first group was composed of patients undergoing resection of colorectal cancer liver metastases (CRLM), while the second enrolled women undergoing cytoreductive surgery for ovarian cancer.

$\mathrm{CRC}$ is the third most common cause of cancer-related deaths worldwide and liver is the most common site of this metastatic disease. Fifteen percent of patients with CRC, are diagnosed with liver metastasis at the same time as their primary tumor and another $15 \%$ will develop liver metastases after resection of the primary tumor [8].
Surgical resection is the primary treatment option for operable metastases but is associated with a recurrence rate of $50-90 \%$ [9-11]. The medical treatment after surgical resection has traditionally been cytotoxic chemotherapy and recent studies have suggested that the immune response has important prognostic implications for CRC patients $[5,12]$.

Ovarian Cancer represents only 3\% of female cancers, but it is the fifth leading cause of cancer-related death in women. Most patients are diagnosed in advanced stage (spread beyond the pelvis, 75\%) due to lack of effective early detection strategies. Surgical debulking is the standard of care followed by chemotherapy with paclitaxel and carboplatin. Unfortunately, the relapse rate after treatment is high, up to $75 \%$. Many different strategies have been attempted to reduce relapse rates with little success. Several studies summarized in a meta-analysis by Hwang et al. [13], have suggested that the composition of TIL also has prognostic significance.

The results of this study demonstrate that the composition of T lymphocytes within CRLM and ovarian tumors is significantly different than peripheral blood T lymphocytes from the same patient. Within the tumor microenvironment, there was a significant increase in both activated Treg and activated $\mathrm{CD}^{+} \mathrm{T}$ cells. Moreover, we found that regardless of the tumor type, tumor location, or whether the tumor was a primary or metastatic deposit, the composition of lymphocytes within the tumors were very similar.

\section{Results}

\section{Patients}

From September 2009 to September 2012, under the approval of our institute's Institutional Review Board (Providence Portland Medical Center, IRB), 16 patients with CRLM (Table 1) and 22 patients with OVC were enrolled in the study. Biopsy specimens and body fluids were received and processed as described in Methods. CRLM patient's age ranged from 30 to 84 years with a median of 67 years. The male to female ratio was 1:1. The primary CRC tumor was resected between 10 to 51 months prior to the resection of CRLM, with a median of 20 months. OVC patients' age ranged from 51 to 88 years with a median of 63.5 years. The majority of patients were diagnosed with serous carcinoma 17/22. Two were diagnosed with endrometroid adenocarcinoma, two with peritoneal carcinoma (1 serous and 1 Muellerian) and one with carcinosarcoma. None of the OVC patients were pre-treated prior to obtaining the tumor resections hence the OVC patients were not included in Table 1.

\section{T cell composition: PBL versus TIL}

TIL isolation was successful for majority of tumor samples obtained. CRLM $(n=16)$ had fewer cells/gram of tissue compared to the OVC samples $(\mathrm{n}=21)$ (median $1.5 \times 10^{6}$ 
Table 1 Patient's characteristics

\begin{tabular}{|c|c|c|c|c|c|c|c|c|}
\hline CRI number & $\begin{array}{l}\text { Age at liver } \\
\text { procedure }\end{array}$ & Sex & $\begin{array}{l}\text { Primary tumor } \\
\text { T stage }\end{array}$ & $\begin{array}{l}\text { Primary tumor } \\
\mathrm{N} \text { stage }\end{array}$ & $\begin{array}{l}\text { Primary tumor } \\
\text { M stage }\end{array}$ & $\begin{array}{l}\text { Post primary } \\
\text { resection chemotx }\end{array}$ & $\begin{array}{l}\text { Adjuvant chemo before } \\
\text { liver resection }\end{array}$ & $\begin{array}{l}\text { Time between } \\
\text { resection and } \\
\text { chemotx (Days) }\end{array}$ \\
\hline CRI 1010 & 60 & $\mathrm{~F}$ & 3 & 0 & 0 & None & $\begin{array}{l}\text { Bevacizumab, Oxaliplatin, } \\
\text { Capecitabine }\end{array}$ & 49 \\
\hline CRI 1012 & 53 & M & 3 & 0 & 0 & $5 F U+$ Leukovorin & FOLFOX + avastin & 209 \\
\hline CRI 1091 & 60 & M & 3 & 2 & 1 & FOLFOX & FOLFOX & 52 \\
\hline CRI 1101 & 47 & $\mathrm{~F}$ & 3 & 1 & 1 & FOLFOX + avastin & FOLFOX + avastin & 36 \\
\hline CRI 1109 & 70 & M & 4 & 1 & 1 & XELOX & XELOX & 52 \\
\hline CRI 1102 & 55 & M & 3 & 2 & 1 & FOLFOX + avastin & FOLFOX + avastin & 133 \\
\hline CRI 1126 & 60 & $\mathrm{~F}$ & 3 & 1 & 1 & FOLFOX & FOLFOX + avastin & 487 \\
\hline CRI 1129 & 79 & M & & & & None & Capecitabine & 53 \\
\hline CRI 1109 & 70 & M & 4 & 1 & 1 & XELOX & XELOX & 123 \\
\hline CRI 1208 & 83 & $\mathrm{~F}$ & 3 & 1 & 0 & XELOX & FOLFIRI + avastin & 103 \\
\hline CRI 1109 & 70 & M & 4 & 1 & 1 & $\mathrm{n} / \mathrm{a}$ & $n / a$ & n/a \\
\hline CRI 1197 & 73 & $\mathrm{~F}$ & & & 1 & FOLFOX & FOLFOX & 89 \\
\hline CRI 1400 & 77 & M & 3 & 0 & 1 & Modified FOLFOX & None & 185 \\
\hline CRI 1405 & 33 & $\mathrm{~F}$ & 3 & 0 & 1 & FOLFOX & FOLFOX & 36 \\
\hline CRI 1404 & 50 & $\mathrm{~F}$ & 3 & 0 & 0 & None & FOLFOX & 35 \\
\hline CRI 1513 & 29 & $\mathrm{~F}$ & $4 a$ & $2 b$ & 0 & FOLFOX & None & None \\
\hline
\end{tabular}

cells/g vs $2.7 \times 10^{6}$ cells $\left./ g\right)$. The median percentages for $\mathrm{CD}^{+} \mathrm{T}$ cells after ficoll separation were $28.2 \%$ in primary OVCs, $53.1 \%$ within the omental metastases, $64.3 \%$ within ascites and 47.5\% from PBMC (Tables 2 and 3). The percentage of $\mathrm{CD}^{+} \mathrm{T}$ cells from CRLM within the lymphocyte gate were, $35.8 \%$ for TIL and 53\% for PBMC. The percentage of $\mathrm{CD}^{+} \mathrm{T}$ cells was calculated as a percentage of a standard FSC and SSC lymphocyte gate [14]. Within the $\mathrm{CD}^{+} \mathrm{T}$ cell population, $\mathrm{CD}^{+} \mathrm{T}$ cells represented $42.4 \%$ of the OVC primary tumor, $48.2 \%$ of the omental metastases and $49.8 \%$ of the CRLM TIL. Approximately $30 \%$ of the infiltrating lymphocytes in all tumor samples were $\mathrm{CD}^{+}{ }^{+} \mathrm{T}$ cells, $30.8 \%$ for CRLM, $34.5 \%$ for primary OVC, $33.4 \%$ for omental metastases and $31.4 \%$ for ascites. The median CD4/CD8 ratio in the blood was very similar for both groups of patients (2.4 and 2.3). The median CD4/CD8 ratio was lower in T cells isolated from tumors (1.6 for CRLM, 1.3 for OVC primaries, 1.4 for omental mets and 1.3 for ascites). Detailed flow cytometric analyses of $\mathrm{CD}^{+}$and $\mathrm{CD}^{+} \mathrm{T}$ cells with other markers were performed as described in Additional file 1: Figure S1. This

Table $2 \mathrm{~T}$ cell distribution in CRLM

\begin{tabular}{lll}
\hline CRC liver metastasis & \multicolumn{2}{l}{ Median (25th-75th percentile) percentages } \\
\cline { 2 - 3 } Cells & Blood $(\mathbf{n}=\mathbf{1 6})$ & TIL $(\mathbf{n}=\mathbf{1 6})$ \\
\hline CD3+ T cells & $53.0(44.2-60.6)$ & $35.8(16.0-42.0)$ \\
CD4+ T cells & $56.45(51.4-73.6)$ & $49.75(32.1-53.9)$ \\
CD8 + T cells & $21.15(14.6-36.7)$ & $30.75(22.1-37.2)$ \\
CD4:CD8 ratio & $2.4(1.4-4.7)$ & $1.6(0.9-2.3)$ \\
\hline
\end{tabular}

scheme was throughout the entire manuscript to calculate percentages in each group.

\section{Characterization of $\mathrm{CD}^{+}{ }^{+} \mathrm{T}$ cell}

A representative dot plot analysis for $\mathrm{CD}^{+}$cells from an OVC sample is shown in Figure 1A. Using the gating scheme in Figure 1A we found that the mean percentage of $\mathrm{CD}^{+} \mathrm{CD}^{+} 5^{+} \mathrm{FoxP}^{+}$Treg within primary and omental mets in ovarian cancer patients were significantly increased compared to PBL (Figure 1C); however, in CRLM patients there was no significant difference in the mean percentage of Treg in TIL compared to blood $(8.1 \%$ and $10.2 \%$ respectively, Figure 1B). We observed that the mean percentage of Treg in the peripheral blood was lower in OVC compared to CRC patients (4.5\% vs $8.1 \%$ ) (Figure $1 \mathrm{~B}-\mathrm{C}$ ). However, the mean percentage of Treg within the primary or the omental OVC metastases was 4 times greater than the blood, reaching an average of $19.2 \%$ and $18.7 \%$ of $\mathrm{CD}^{+} \mathrm{T}$ cells respectively (Figure $1 \mathrm{C}$ ). We also assessed Ki-67 expression (proliferation marker) in Treg within the 2 groups of patients, (Figure 1A, D-E). As shown in Figure $1 \mathrm{D}$ and $\mathrm{E}$, the percentage of dividing Treg was similar in the tumors and peripheral blood for both tumor types.

\section{The phenotype of $\mathrm{CD}^{+} \mathrm{CD}^{+} 5^{+} \mathrm{FoxP}^{+} \mathrm{T}$ cells: $\mathrm{TIL}$ versus PBMC}

Since there are subtypes within Treg, that exhibit differing abilities to suppress T cell function, we determined whether the presence of these sup-phenotypes differed by location 
Table 3 T cell distribution in OVC tumor specimens

\begin{tabular}{|c|c|c|c|c|}
\hline \multirow{2}{*}{$\begin{array}{l}\text { Ovarian } \\
\text { Cells }\end{array}$} & \multicolumn{4}{|c|}{ Median (25th-75th percentile) percentages } \\
\hline & Blood $(n=21)$ & Ascites $(n=16)$ & TIL $(n=21)$ & Met $(n=17)$ \\
\hline CD3+ T cells & $47.5(31.5-62.0)$ & $64.30(40.2-75.2)$ & $28.2(17.8-52.3)$ & $53.1(25.1-62.3)$ \\
\hline CD4+ T cells & $62.3(51.9-73.8)$ & $49.0(35.9-64.5)$ & $42.4(36.1-45.1)$ & $48.2(40.8-53.3)$ \\
\hline CD8+ T cells & $25.1(18.7-36.6)$ & $31.4(25.8-48.5)$ & $34.5(22.6-47.5)$ & $33.4(23.1-39.0)$ \\
\hline CD4:CD8 ratio & $2.3(1.4-4.0)$ & $1.3(0.8-2.5)$ & $1.3(0.8-1.8)$ & $1.4(1.1-2.0)$ \\
\hline
\end{tabular}

and tumor type. Because HLA-DR/MHC class II expression is a signature of activation for both Treg and effector $\mathrm{CD}^{+} \mathrm{T}$ cell populations we assessed its expression on TIL and PBL. As shown in Figure 2A and B, Treg present in the primary tumors and mets have increased HLA-DR expression compared to $\mathrm{PBL}$ for both CRC and OVC patients $(69 \%$ and $70 \%$ compared to 31.7 and $37 \%$ respectively). We also found that the frequency of non-Treg/ effector $\mathrm{CD}^{+} \mathrm{T}$ cells expressing HLA-DR is increased in the TIL compare to blood (Figure 2C). However, the
A PBL
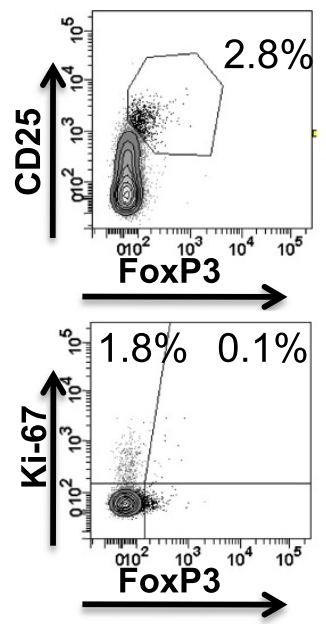

B

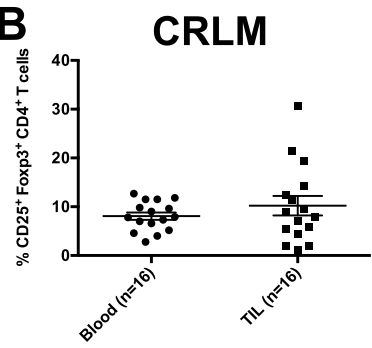

D CRLM

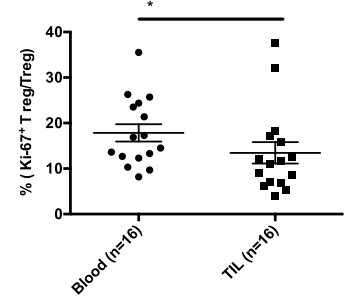

Ascites
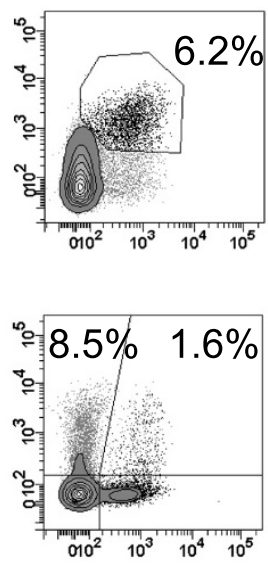

Omental

Primary

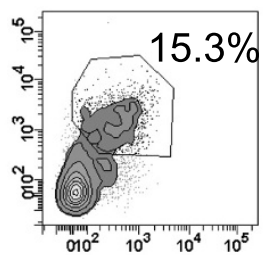
Metastases
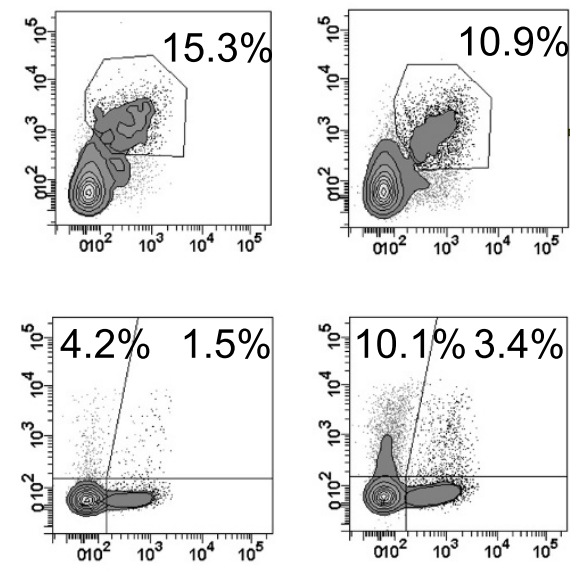

C Ovc

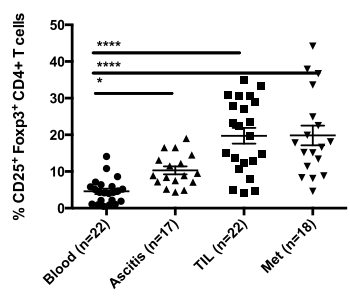

E OVC

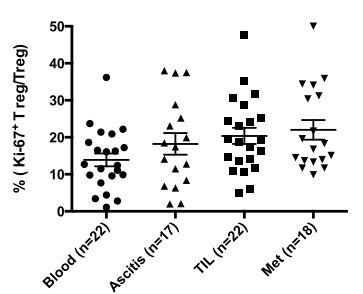

Figure $1 \mathrm{CD}^{+} \mathbf{T}$ cell analysis. A. $\mathrm{CD}^{+} \mathrm{CD}^{+} \mathrm{T}$ cells collected from PBL, ascites, primary tumor and omental metastases were analyzed for $\mathrm{CD} 25$ and FoxP3, upper panels and Ki-67 and Foxp3, lower panels. Percentage of CD25 FoxP3 ${ }^{+}$, Treg in PBL and TIL of CRC patients $(n=16) \mathbf{B}$, and in OVC patients $(n=22)$ C. Percentage of proliferating Treg in CRC samples (D) and in OVC samples (E). 

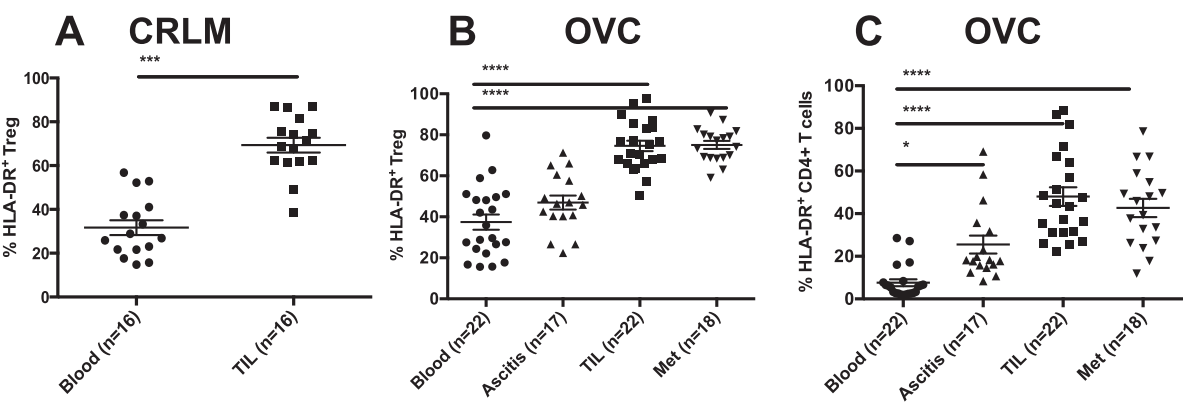

Figure 2 HLA-DR expression on Treg and non-Treg CD4 ${ }^{+}$T cells. $\mathrm{CD}^{+} \mathrm{CD} 4^{+} \mathrm{CD} 25^{+} \mathrm{FoxP}^{+}$Treg cells were analyzed for HLA-DR expression in CRC samples (A) and OVC samples (B). C. HLA-DR expression on CD4 ${ }^{+}$Foxp3 $3^{-}$non-Treg in OVC samples.

mean fluorescense intensity (MFI) for HLA-DR was significantly greater in the Treg TIL compared to the conventional CD4 ${ }^{+}$TIL, 4225.8 and 4566.7 for primary tumor and omental metastases Treg compared to 2976.5 and 2639.8 for conventional CD4 $4^{+}$TIL in primary tumor and omental metastases $(\mathrm{p}=0.0006$ and $<0.0001$, respectively) (data not shown). The data suggest that the Treg within the tumor are more activated than the conventional $\mathrm{CD} 4^{+}$TIL within these progressively growing tumors.

Given that CRLM and OVC patients have a very different treatment and clinical history it was somewhat surprising that the increase in HLA-DR expression by Treg from tumors was consistent for both of these tumor types (Figure 2A-B). We further investigated whether other markers known to be expressed by activated Treg, were upregulated in the tumor microenvironment. We examined CD39, CTLA-4 and Helios all of which have been associated highly suppressive Treg activity. CD39 is an ectonucleoside triphosphate diphosphohydrolase, that hydrolases ATP and thus depletes ATP from the extracellular milieu and has been associated with highly suppressive Treg function $[15,16]$. Helios has been characterized as a Treg lineage marker and is a transcription factor that has also been associated with greater suppressive activity [17]. Fifteen OVC samples were analyzed for the expression of Helios and the frequency of Helios expressing Treg was significantly higher in the OVC primary tumors and omental metastases when compared to PBL $(79.6,76.2$ versus 50.1\%) (Figure 3A). Co-expression of HLA-DR and Helios was also higher on Treg from TIL (57.5\%) and omental metastases $(58.8 \%)$ compared to blood $(23.6 \%)$ or ascites (34.7\%) (Figure 3B-C). Eleven OVC samples were assessed for CD39 expression. Between $60-70 \%$ of Treg isolated from primary tumors and omental metastases were positive for CD39, while only $30 \%$ of the PBL Treg were positive for CD39 (Figure 3D-E). The MFI of CD39 was also significantly higher on Treg collected from TIL and Met compared to PBL (1842.5, 964.1 vs 441.9, with a $\mathrm{p}<0.001$ and $<0.05$ respectively) (data not shown). When we assessed CD39 on the non-Treg CD4, 32.7\% of TIL non-Treg CD4 $4^{+} \mathrm{T}$ cells expressed CD39 compared to $10.6 \%$ of PBL non-Treg CD4 ${ }^{+} \mathrm{T}$ cells $(\mathrm{p}<0.05)$ (data not shown). The CD39 MFI was greater on Treg compared to non-Treg CD4 T cell population. Co-expression of HLADR and CD39 was found on 50\% of the Tregs within the primary tumors and Mets while only $20 \%$ of PBL Treg coexpressed these two markers (Figure 3E). Another inhibitory protein, CTLA-4 is expressed by both effector and regulatory $\mathrm{T}$ cells and it is known for suppressing $T$ cell function [18]. There was no significant difference in percentage of Treg that expressed CTLA-4 in PBL, primary tumor and metastases Treg (Figure 3F). However, the co-expression of CTLA-4 and CD39 is significantly higher in the TIL (61.2\%) compared to PBL (20.3\%) (Figure 3G and Tables 4 and 5).

\section{$\mathrm{HLA}^{-\mathrm{DR}^{+}}$Treg isolated from tumors have greater suppressive function}

We obtained sufficient surgical material from two OVC patients to compare the ability of HLA-DR ${ }^{+}$and HLA-DR ${ }^{-}$ Treg to suppress IFN $\gamma$ production from activated peripheral blood CD4 T cells. CD3 enriched T cells from tumors were stained with anti-CD4, anti-CD25, anti-CD127 and anti-HLA-DR and were gated on the CD25 ${ }^{\text {hi }} \mathrm{CD} 127^{\text {lo }}$ $\mathrm{CD}^{+} \mathrm{T}$ cells, which identifies the Treg population in tumors $[19,20]$. These cells were then sorted into HLA-DR positive and negative subsets and their ability to inhibit $T$ cell function was assessed. The HLA-DR ${ }^{+}$Treg were $2-4$ times more suppressive than HLA-DR ${ }^{-}$Treg as measured by the inhibition of IFNY secretion by activated CD4 $\mathrm{T}$ cells (Figure 4A-B and Additional file 2: Figure S2). These results are supportive of recent manuscripts [21,22] showing that the tumor microenvironment is greatly enriched for highly active Treg and this population most likely plays a role in dampening effector $\mathrm{T}$ cell responses within the tumor.

\section{Characterization of $\mathrm{CD}^{+}$TIL}

$\mathrm{CD}^{+} \mathrm{T}$ cell immune infiltrates have been characterized in several different human tumor types [4]. In CRC, an increase in $\mathrm{CD}^{+}$infiltrates in the primary tumor has been 


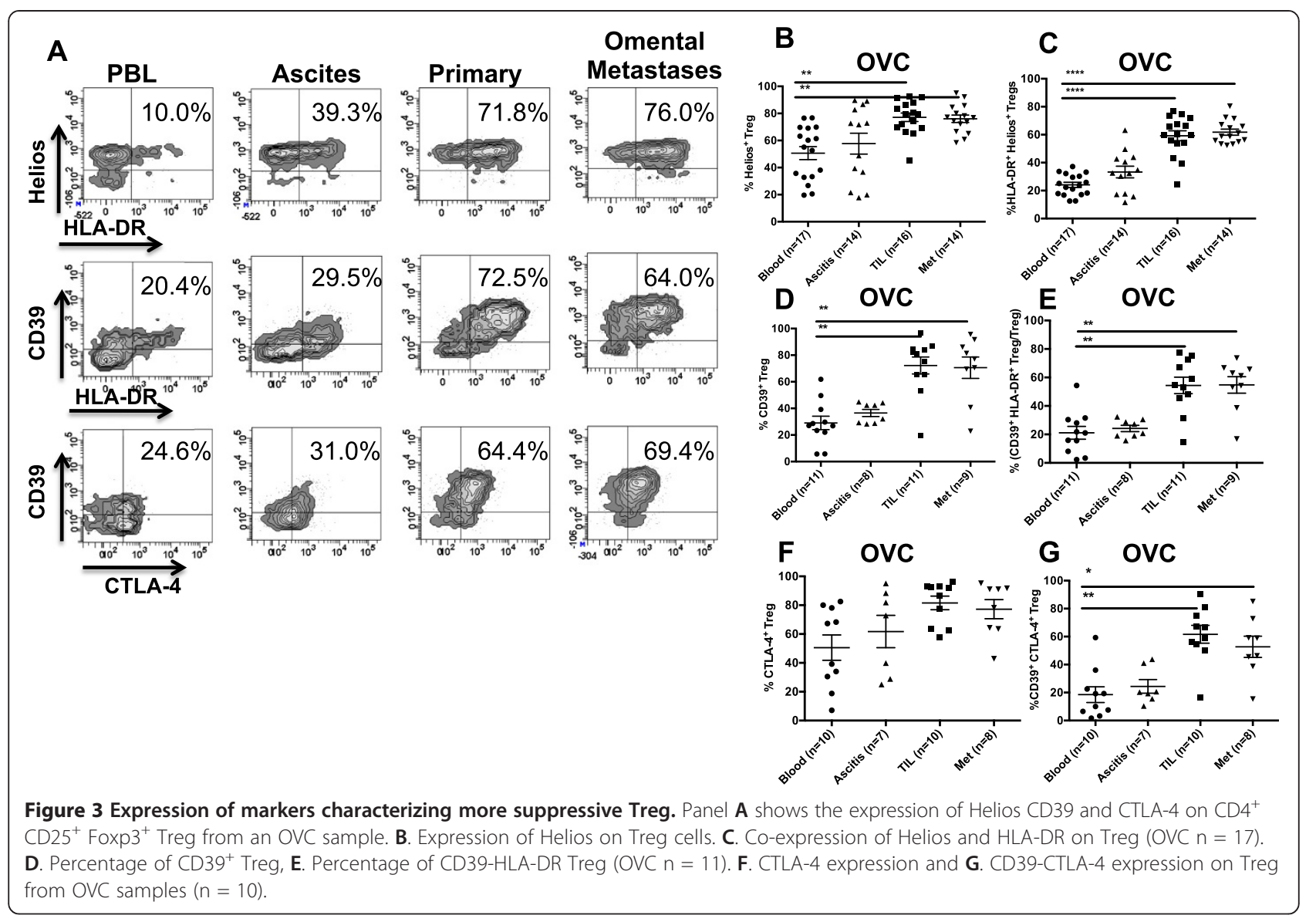

shown to correlate with lack of metastases and decreased tumor progression $[23,24]$. The majority of these studies used IHC to assess cellular infiltrates [23,24] and very few studies describe complex CD8 phenotype and proliferative status of CD8 T cells isolated from tumors. In this study, we focused on co-expression of the membrane-bound activation markers CD38 and HLA-DR expressed on CD8 ${ }^{+}$ $T$ cells. Co-expression of these two proteins has been used to identify Ag-activated vaccine-specific $\mathrm{CD}^{+} \mathrm{T}$ cells in humans that had recently been inoculated with a yellowfever vaccine [25]. Hence in the context of tumor infiltrating lymphocytes co-expression of these to markers may identify recently activated tumor-antigen specific $\mathrm{T}$ cells. The percentage of $\mathrm{CD}_{3} 8^{+} / \mathrm{HLA}_{-} \mathrm{DR}^{+} \mathrm{CD}^{+} \mathrm{T}$ cells in the peripheral blood of CRLM and OVC patients was low, between $8-10 \%$. In both CRLM and OVC the percentage of

Table 4 Percentage distribution of $\mathrm{CD}^{+} \mathrm{T}$ cell phenotypes: summary of $\mathrm{CD4}^{+} \mathrm{T}$ cells phenotypes in CRLM patients

\begin{tabular}{lll}
\hline Mean\% cell population (+/- SD) & PBL & TIL \\
\hline CD25+ Foxp3+ CD4+ T cells & $8.1(+/-3.0)$ & $10.2(+/-8.0)$ \\
Ki-67+ Treg cells & $17.9(+/-7.6)$ & $13.5(+/-9.4)$ \\
HLA-DR + Treg cells & $31.7(+/-13.5)$ & $69.4(+/-13.5)$ \\
\hline
\end{tabular}

$\mathrm{CD} 8^{+} / \mathrm{HLA}^{-D R^{+}} \mathrm{CD}^{+} \mathrm{T}$ cells is increased five-fold and four-fold in TIL compared to PBL in ovarian cancer and CRC patients, respectively (Figure 5D-E). We also assessed $\mathrm{Ki}-67$ expression to determine the proportion of dividing $\mathrm{CD}^{+} \mathrm{T}$ cells in both tumor types. The frequency of dividing $\mathrm{PBL} \mathrm{CD}^{+} \mathrm{T}$ cells in both patient groups is approximately $3 \%$ (Figure 5A-C). However, the frequency of $\mathrm{Ki}-67^{+} \mathrm{CD}^{+} \mathrm{T}$ is significantly higher in the tumors from CRLM patients, $9.1 \%$ and in the OVC primary tumors and omental metastases, $12.3 \%$ and $12.5 \%$ respectively, compared to PBL.

Cytokine mRNA levels in CD4 T Cells from TIL versus PBL $\mathrm{CD}^{+}{ }^{+} \mathrm{T}$ cells were enriched from both PBL and TIL as described in Methods. The purity of $\mathrm{CD}^{+} \mathrm{T}$ cells was between $85-95 \%$. Cytokine mRNA was quantitated by PCR to investigate whether there were any differences in cytokine RNA obtained from blood versus tumor CD4 ${ }^{+}$ $\mathrm{T}$ cells. No differences were observed for IL-2, INF $\gamma$, TGF $\beta$, IL-3, IL-4 or IL-10 and very low levels of IL17A and IL-21 mRNA were detected in both PBL and TILs. However, IL-6 mRNA was detected at high levels from $\mathrm{CD}^{+} \mathrm{TIL}$ when compared to PBL of the same patients (Figure 6). Quantitative PCR assessment for IL-6 in 
Table 5 Percentage distribution of $\mathrm{CD4}^{+} \mathrm{T}$ cell phenotypes: summary of $\mathrm{CD4}^{+} \mathrm{T}$ cells phenotypes in OVC patients

\begin{tabular}{lllll}
\hline Mean\% cell population (+/- SD) & PBL & Ascitis & TIL & Met \\
\hline CD25+ Foxp3+ CD4+ T cells & $4.6(+/-3.4)$ & $10.31(+/-4.4)$ & $19.7(+/-10.1)$ & $19.8(+/-11.4)$ \\
Ki-67+ Treg cells & $13.9(+/-8.2)$ & $18.2(+/-12)$ & $20.4(+/-10.2)$ & $22(+/-11.3)$ \\
HLA-DR + Treg cells & $37.4(+/-17.4)$ & $47.0(+/-14.1)$ & $74.6(+/-12.1)$ & $75.1(+/-8.3)$ \\
HLA-DR + CD4+ T cells & $7.6(+/-7.7)$ & $25.5(+/-17.3)$ & $48(+/-20.6)$ & $42.7(+/-18.2)$ \\
Helios + Treg cells & $50.7(+/-19.8)$ & $58.7(+/-27.1)$ & $77.2(+/-12.6)$ & $76.3(+/-11.0)$ \\
HLA-DR + Helios + Treg cells & $24.1(+/-7.7)$ & $35.1(+/-15.9)$ & $59.2(+/-14.2)$ & $62(+/-8.7)$ \\
CD39+ Treg cells & $29.1(+/-16.7)$ & $43.1(+/-20.9)$ & $72.2(+/-21.1)$ & $67.5(+/-23.7)$ \\
HLA-DR + CD39+ Treg cells & $21.1(+/-15)$ & $28.8(+/-15)$ & $54.4(+/-19.3)$ & $53.4(+/-18.1)$ \\
CTLA-4 Treg cells & $50.6(+/-27.8)$ & $63.8(+/-28)$ & $81.6(+/-14.9)$ & $77.1(+/-20.2)$ \\
CD39+ CTLA-4+ Treg cells & $18.5(+/-17.8)$ & $27.2(+/-14.2)$ & $61.7(+/-20.3)$ & $53.6(+/-23)$ \\
\hline
\end{tabular}

$14 \mathrm{OVC}$ and $10 \mathrm{CRC}$ patient samples showed significant increases in IL- 6 mRNA production by $\mathrm{CD}^{+}{ }^{+} \mathrm{T}$ cells when TIL were compared to PBL. In 7 out of 14 OVC patients samples, there was an increase in IL-6 mRNA both within the primary tumors and metastases when compared to blood, 4/14 revealed an increase in the metastases but not the tumor and for 3/14 there was no difference when comparing the blood, tumor and metastases. The foldincrease varied from 5-fold up to over a 1000-fold increase and the average was 12 -fold. In the 10 CRC samples analyzed, 8 out of 10 revealed increased levels of IL-6 mRNA in TIL compared to blood. Similar to the ovarian cancer samples, the fold-increases varied from 2 to over a 1000-fold (average increase was 120-fold). We also quantified IFN- $\gamma$ message from all the samples shown in Figure 6. As opposed to IL-6 no difference for IFN- $\gamma$ mRNA was observed when comparing CD4 TIL to PBL within the same patient (data not shown).

\section{Discussion}

This work demonstrates the utility of using a 10 color flowcytometry panel for analyzing TIL from freshly isolated tumor samples and shows that extensive information can be obtained using this approach. 10-color flow cytometry allows for a more detailed phenotypic characterization of $\mathrm{T}$ cell subsets when compared to standard IHC techniques, which have been used in previous TIL studies [26]. These analyses show several significant phenotypic differences in the composition of TIL when compared to PBL. Our results also suggest, that regardless of the tumor type (CRC and OVC), the site of the disease (primary or metastatic lesions), or treatment status, the composition of TIL was surprisingly similar in these progressively growing tumors. We will began exploring other human malignancies in the future to ascertain whether this phenotypic pattern holds true across several different tumor types.

When comparing the TIL immune phenotype to PBL, we found several significant differences. OVC TIL contained a higher percentage of Treg compared to PBL (4.6\% PBL compared to $19.7 \%$ ), while there was no difference in Treg percentage in the CRC tumors compared to PBL. In both tumor types, Treg infiltrating the tumor were qualitatively different expressing higher levels of activation markers when compared to blood. These data show that proteins associated with a highly suppressive Treg phenotype $[6,7,16,17]$ were more abundant in $\mathrm{T}$ cells that infiltrate
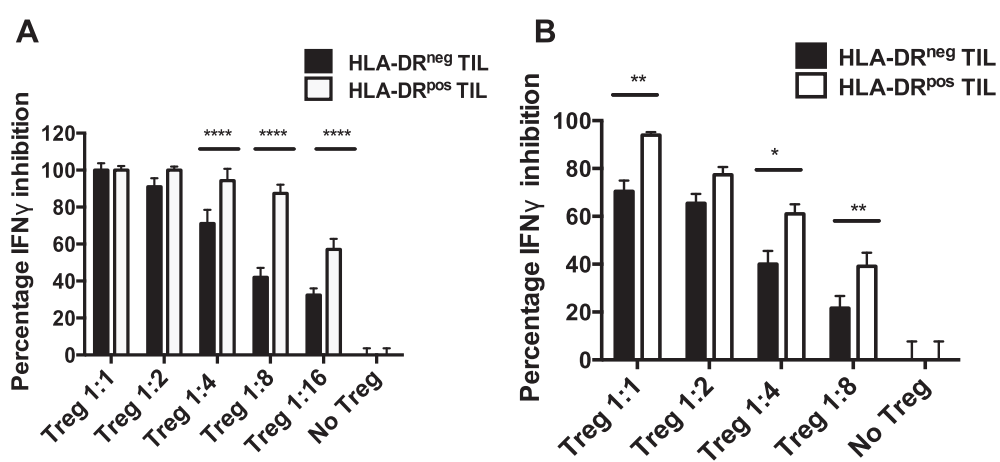

Figure 4 HLA-DR + TIL Treg have a higher suppressive potency. $C D 3^{+} C D 4^{+} C D 25^{\text {high }}$ and $C D 127^{\text {low }}$ Treg were sorted for HLA-DR+/-. Their suppressive function was measured in vitro by their capacity to suppress INFY secretion by effector $C D 4^{+}$T cells. Panel $\mathbf{A}$ and $\mathbf{B}$ represent 2 individual OVC patients. 

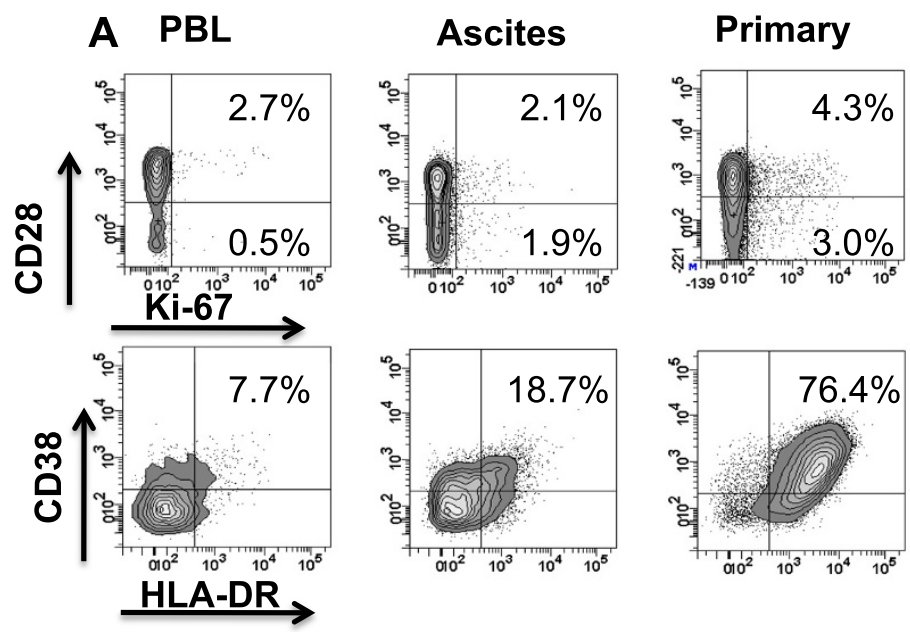

\section{Omental Metastases}
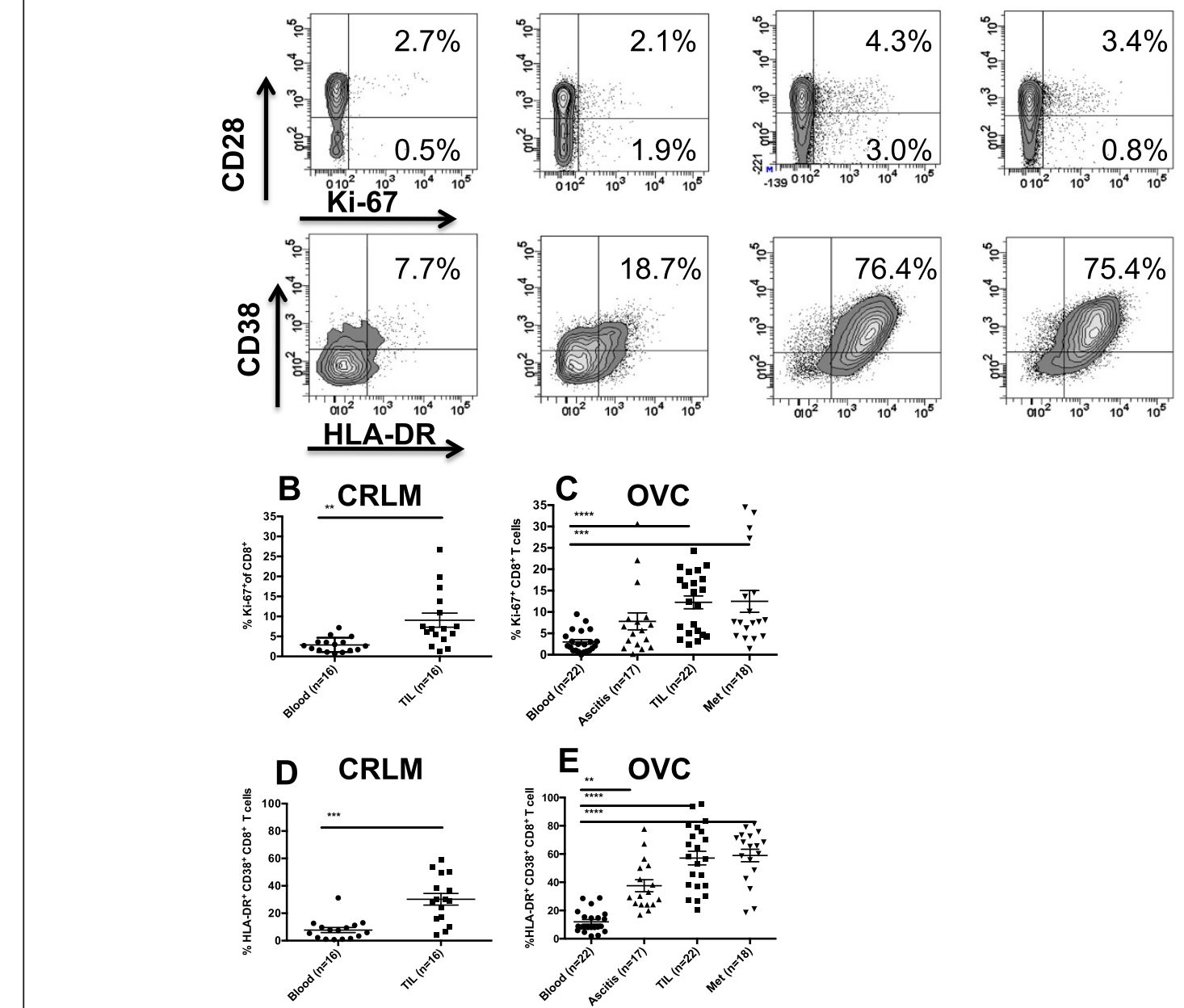

Figure $5 \mathrm{CD}^{+} \mathbf{T}$ cells phenotype in CRC and OVC patients. A. An example of flow cytometric analysis of $\mathrm{CD} 3^{+} \mathrm{CD} 8^{+} \mathrm{T}$ cells analyzed for $\mathrm{CD} 28$ and Ki-67, upper panels, and HLA-DR and CD38, lower panels. Percentage of Ki-67 $7^{+}$CD8 T cells in CRC samples $(n=16) \mathbf{B}$. and OVC samples $(n=22)$ C. Co-expression of CD38 and HLA-DR on CD8 ${ }^{+}$T cells in CRC samples (D) and OVC samples (E).

tumors when compared to peripheral blood. These results also suggest that there is a selective accumulation of activated Treg within the tumor microenvironment regardless of the tumor type or location; primary or secondary site. These findings may lend credence to the hypothesis that the immune system fails to immunologically reject tumors because highly activated Treg are suppressing effector responses within the tumor microenvironment. Others have shown that the some of proteins studied within this manuscript mark Treg with a greater suppressive capacity $[21,22]$. This is an observation we confirmed by showing that sorted HLA-DR ${ }^{+}$Treg were more suppressive when compared to HLA-DR ${ }^{-}$Treg in two OVC patient tumor samples. Recent studies have shown that Treg isolated from CRLM have potent immune suppressive properties $[27,28]$. These studies did not analyze the phenotype of the Treg population, but they clearly demonstrated that
Treg isolated from CRLM were more suppressive than Treg from PBL or tumor non-invaded tissue. We also found that infiltrating lymphocytes from both tumor types had a higher CD8/CD4 T cell ratio compared to PBL (see Table 1). Moreover, the $\mathrm{CD}^{+} \mathrm{T}$ cells within the tumor showed a greater propensity towards activation as measured by increased co-expression of CD38/HLA-DR. There was also an increased frequency of $\mathrm{Ki}-67^{+} \mathrm{CD}^{+} \mathrm{T}$ cells in the TIL compared to PBL. While there is an increase in CD8 $\mathrm{T}$ cell activation and proliferation among patients' TIL, it is clearly not sufficient to eradicate the tumor. There may be several explanations as to why these activated CD8 $\mathrm{T}$ cells are incapable of eradicating tumors. The $\mathrm{CD}^{+}$ $T$ cells within these tumors were found among suppressive cells including Treg (Tables 4 and 5), as well as MDSC [29] (not analyzed here), which could help to explain their failure to eradicate the tumor. These CD8 T cells could 


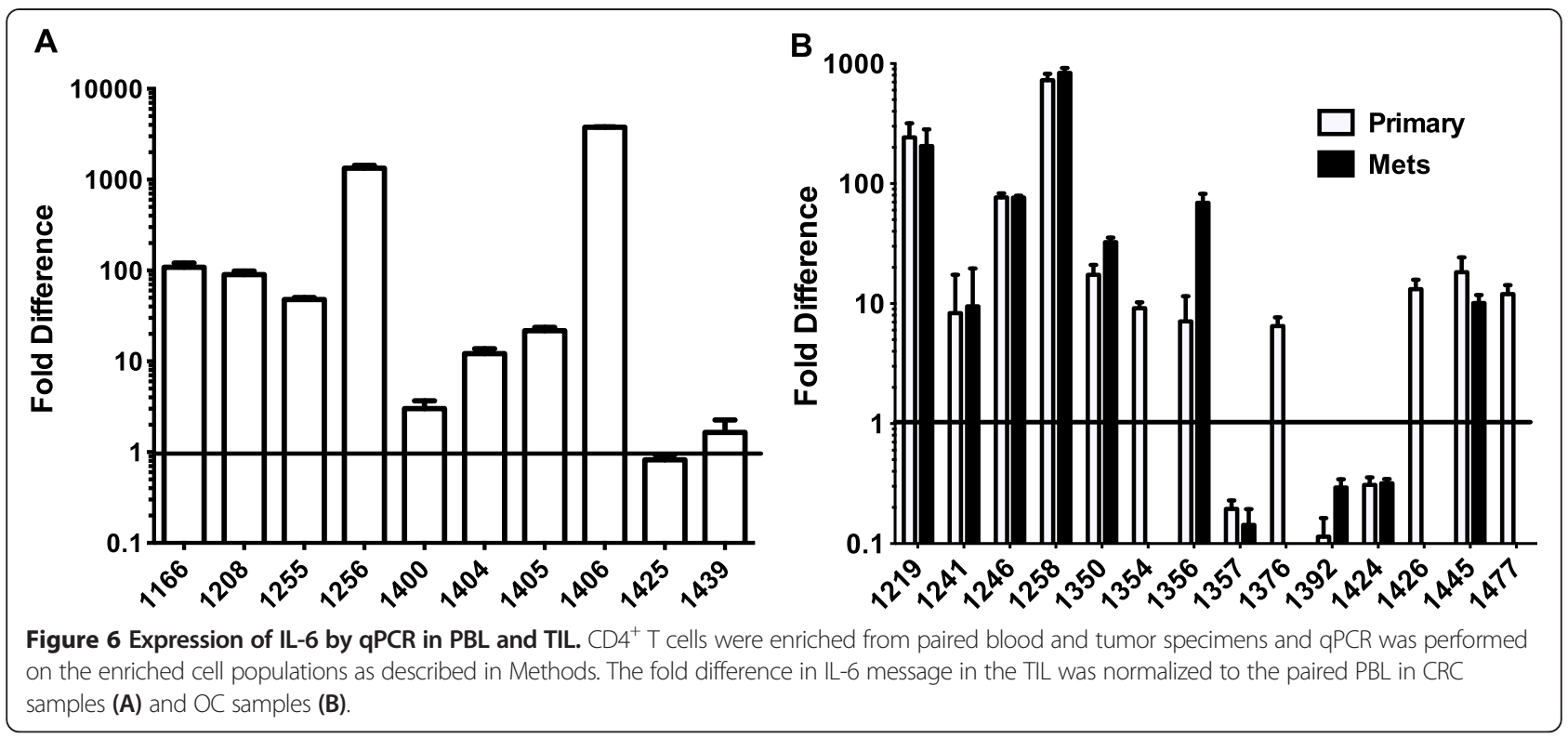

also express a host of exhaustive markers, such as PD-1 or Tim-3 (not assessed in this study), which could also limit their functional activity as shown by others [30,31]. Another possibility is that the cytokine milieu created by cells within the tumor microenvironment could have suppressive effects on T cell function. Hence, we also investigated levels of cytokine transcripts produced by CD4. ${ }^{+}$TIL isolated from progressively growing tumors. While we have found an increase in activated Treg, we also found that the $\mathrm{CD}^{+}{ }^{+}$TIL express higher levels of IL- 6 mRNA compared to $\mathrm{CD} 4^{+}$PBL. The increased expression of IL- 6 mRNA observed within the tumor, if translated to protein, could also contribute to an immune-suppressed environment potentially through increased pSTAT3 upregulation within immune cells found in the tumor [32-34].

The two patient populations in this study had different clinical treatment histories. The CRLM patients typically had a preexisting history of cancer prior to the metastatic cancer resection, and in most cases had undergone previous resection of their primary tumor followed by chemotherapy (Table 1). In contrast, the patients with ovarian cancer typically had no treatment prior to their cytoreductive surgery. The tumor types analyzed also varied by stage of tumor development; liver metastatic tissue for CRC and primary tumors, omental metastases, and/or ascites for OVC patients. However, despite these differences, we observed many similarities in the TIL composition that were noted across different tumor types and sites of tumor growth.

Using a 10-color flow panel we provide a detailed analysis of the TIL composition from two different tumor types and found as expected that the TIL phenotype is much different than that of PBL. We can use these analyses as a phenotypic template of TIL isolated from progressively growing tumors and in the future compare these results to the phenotype of TIL isolated from patients treated with immunotherapy (e.g. anti-CTLA-4, anti-PD-1 and anti-OX40). Understanding how immunotherapies work by potentially changing the TIL composition and phenotype could lead to a more mechanistic approach to tumor immunotherapy, as most of the analyses in immunotherapy trials to date have analyzed PBL. This work also serve as a detailed platform for understanding the $\mathrm{T}$ cell phenotypes within progressively growing tumors and future studies will investigate the $\mathrm{T}$ cell phenotypes from other human malignancies in order determine similarities and differences to the results shown in this study. Ultimately, a greater understanding of the frequency and function of $\mathrm{T}$ cell infiltrates within progressively growing human tumors will allow us to better understand how to treat patients with immunotherapy to elicit $\mathrm{T}$ cell responses with greater clinical efficacy.

\section{Conclusion}

The results presented in this study show that the composition of immune infiltrates isolated from patients harboring different tumor types is very similar. We found that both colorectal liver metastases and ovarian cancer have a greater percentage of activated $\mathrm{T}$ regulatory cells as well as a higher percentage of activated $\mathrm{CD}^{+} \mathrm{T}$ cells when compared to peripheral blood of the same patients. We also found that CD4 T cells isolated from both tumor types have an increase in mRNA for IL-6 compared to peripheral blood CD4 T cells. This manuscript provides a foundation for the activation profile of tumor infiltrating $\mathrm{T}$ cells in two different progressively growing tumor types and could be used as baseline when assessing immunologic changes in patients treated with immunotherapy. 


\section{Methods}

\section{Collection and isolation of lymphocytes from peripheral blood and ascites}

Peripheral blood was collected in heparinized tubes just prior to or during surgery. Ascites cells were centrifuged and the pellet was resuspended in XVivo media (Lonza) and mononuclear leukocytes were separated from red blood cells and or tumor cells by Ficoll-Paque Plus (GE Healthcare, 17-1440-02) density gradient centrifugation for both ascites and peripheral blood. The leukocyte fraction was harvested, washed in PBS and counted prior to being stained or enriched.

\section{Isolation of tumor-infiltrating lymphocytes}

Specimens were obtained at the time of surgery. Single cell suspension were obtained under sterile conditions in PBS, solid tumors were cut into $1-3 \mathrm{~mm}^{3}$ pieces and digested at room temperature for 1 hour on a magnetic stirring apparatus in a solution containing DNAse (Roche, 4536282001), collagenase (Sigma, C5138), halyuronidase (Sigma, H-6254) as well as human albumin (CSL Behring, 0053-7680-32) in RPMI (Lonza, 12-702Q). Enzymatically dissociated tumor was filtered through a $70 \mu \mathrm{m}$ filter. Filtered samples were then diluted 1:2 with RPMI and ficolled as described above to obtain a leukocyte-enriched fraction. Cells were then washed three times in PBS $\left(1^{\text {st }}\right.$ wash @ $1,000 \mathrm{rpm}$ for 10 minutes to remove debris, then $2 \mathrm{x}$ $@ 1,250$ for 5 minutes) and counted. Leukocytes were resuspended at $10 \times 10^{6} \mathrm{cells} / \mathrm{ml}$ in PBS prior to staining or enrichment.

\section{Flow cytometry analysis}

Single cell suspensions of leukocytes from blood, ascites, tumor or omental metastases were stained with the following monoclonal antibodies: anti-CD3 APC-H7 (BD Pharmingen, 560176), anti-CD4 eFlour 450 (eBioscience, 48-0048-42), anti-CD8 Pacific Orange (Invitrogen, $\mathrm{MH}$ CD0830), anti-CD25 APC (BD Pharmingen, 555434), or anti-CTLA-4 APC (BD Pharmingen, 555855), anti-CD28 PerCpCy5.5 (eBioscience, 45-0289-42), anti-CD38 PE-TR (Invitrogen, MHCD3817), anti-HLA-DR PE-Cy7 (BD Biosciences, 335795), anti-FoxP3 PE (eBioscience, 12-477742), anti-ki67 FITC (BD Pharmingen, 556026) or CD39 FITC (BD Pharmingen, 561444) or anti-Helios (Biolegend, 137214). Cells were stained in FACs buffer (1\%FBS in PBS with $0.01 \% \mathrm{NaN}_{3}$ ) and fixed according to the ebioscience FoxP3 Fix-Perm kit protocol (eBioscience, 00-5521-00). All samples were run on a BD LSRII Flow cytometer and analysed by FACSDiva BD. Briefly, for every single flow cytometric antibody, we have used Fluorescent Minus One (FMO), to discriminate between positive and negative cells [35].

\section{Treg sort}

Lymphocytes from ascites, prepared as described above, were stained with anti-CD3, anti-CD4, anti-CD25, anti CD127 and anti-HLA-DR and sorted for T effector cells $\left(\mathrm{CD}^{+}, \mathrm{CD}^{+}, \mathrm{CD} 25^{\text {low }}\right.$ and $\left.\mathrm{CD} 127^{\text {high }}\right)$ and Treg: $\mathrm{CD}^{+}$, $\mathrm{CD} 4^{+}, \mathrm{CD} 25^{\text {high }}, \mathrm{CD}_{12} 7^{\text {low }}$ and $\mathrm{HLA}-\mathrm{DR}^{+}$and $\mathrm{CD} 3^{+}, \mathrm{CD} 4^{+}$, $\mathrm{CD} 25^{\text {high }}, \mathrm{CD} 127^{\text {low }}$ and HLA-DR ${ }^{-}$. Cells were sorted on an Aria sorter (BD).

\section{Treg suppressive assay}

Effector (30-50,000/well) and Treg were plated at ratio described in Figure 4, and stimulated with soluble antiCD3 $(1 \mu \mathrm{g} / \mathrm{ml})$ and CD28 $(2 \mu \mathrm{g} / \mathrm{ml})$ as previously described [36]. Supernatents were harvested at Day 3 and 5 and IFN $\gamma$ was measured by ELISA (eBioscience).

\section{CD4 enrichment}

Enrichment of $\mathrm{CD} 4^{+} \mathrm{T}$ cells from blood and tumor samples was achieved using the EasySep Human CD4 Negative Enrichment kit (StemCell Technologies, 19052). The CD4 population was further purified, using the EasySep Human CD4 Positive Selection kit (StemCell Technologies, 18052).

\section{qPCR}

The RNA from $\mathrm{CD}^{+}$lymphocyte populations was isolated using the QIAshredder (QIAGEN, 79654) and RNeasy Mini kits (QIAGEN, 74104). The isolated RNA was treated with Turbo DNase (Ambion, AM1907) and quantified by optical density. $1 \mu \mathrm{g}$ of treated RNA was used to prepare cDNA using the RevertAid First Strand cDNA Synthesis kit (Fermentas, K1621). Samples were then analyzed by qPCR on the Applied Biosystems Step One Plus using $250 \mathrm{ng}$ of cDNA per reaction with reactions set up in triplicate. The reactions utilized the Maxima Probe/ROX qPCR Master Mix (Fermentas, K0232). Samples were analyzed using FAM/TAMRA probes for IL-6 expression (Invitrogen, Hs00985639_m1), IL-17 expression (Invitrogen, Hs00174383_m1) and IFNY expression (Invitrogen, Hs00989291_m1). GAPDH was used as the endogenous mRNA control (Invitrogen, Hs02758991_g1). cDNA from normal donor PBMCs stimulated with PMA/ionomycin for 11 hours was used as the calibrator sample. The results were then analyzed using the Comparative Ct Method of relative quantification.

\section{Additional files}

Additional file 1: Figure S1. Flow cytometry gating strategy. Tumor samples were processed as described in Methods. Single cell suspensions were analyzed by flow cytometry. FSC and SSC were used to determine the lymphocyte population. $\mathrm{CD}^{+} \mathrm{T}$ cells were subdivided into $\mathrm{CD}^{+}$and $\mathrm{CD}^{+}$ $T$ cells. CD4 ${ }^{+} T$ cells were analyzed for the expression of CD25 and FoxP3 (Treg). CD39, HLA-DR, CTLA-4 and Helios were used to characterize highly suppressive Treg. Both non-Treg and Treg were assessed for proliferation by 
using Ki-67. Expression of CD38 and HLA-DR on $\mathrm{CD}^{+} \mathrm{T}$ cells was used to characterize recently activated $C D 8^{+} T$ cells and Ki-67 identified proliferating $\mathrm{CD} 8^{+} \mathrm{T}$ cells.

Additional file 2: Figure S2. HLA-DR ${ }^{+} T L L$ Treg have a higher potency to suppress INFy secretion. $\mathrm{CD}^{+}, \mathrm{CD}^{+}, \mathrm{CD} 25^{\text {high }}$ and $\mathrm{CD} 127^{\text {low }}$ Treg were sorted for HLA-DR ${ }^{+} /$. They were co-cultured in triplicate with $\mathrm{CD}^{+} \mathrm{CD}^{2} 5^{-} \mathrm{T}$ cells at different cell ratio. INFY secretion was measured in the supernatant by ELISA. Panel A and Panel B represent 2 individual patients.

\section{Competing interests}

The authors declare that they have no competing interests.

\section{Authors' contributions}

MKB designed the study, analyzed and interpreted data and wrote the manuscript. LC, JV CGT, RM and DH performed the experiments. PN, JM, PT, $R W$, JTV, CH, and PH were involved in patients care and performed the surgical procedures. ADW designed the study interpreted data and wrote the manuscript. All authors read and approved the final manuscript.

\section{Acknowledgements}

The authors thank Dr. Walter Urba for critical reading of the manuscript and Helena Hoen for her help with the statistical analyses.

\section{Author details}

${ }^{1}$ Earle A. Chiles Research Institute, Providence Cancer Center, Portland Providence Medical Center, 4805 NE Glisan St, Portland, Oregon 97213, USA ${ }^{2}$ Agonox Inc, 4805 NE Glisan St, Portland, Oregon 97213, USA. ${ }^{3}$ Providence Gynecologic Oncology, Providence Cancer Center, Portland Providence Medical Center, 4805 NE Glisan St, Portland, Oregon 97213, USA. ${ }^{4} \mathrm{OHSU}$, division of oncological surgery and OHSU Knight Cancer Center, 3303 SW Bond Ave, Portland, OR 97239, USA. ${ }^{5}$ Providence Surgical Oncology, Providence Cancer Center, Portland Providence Medical Center, 4805 NE Glisan St, Portland, Oregon 97213, USA.

Received: 27 May 2014 Accepted: 22 September 2014

Published online: 18 November 2014

\section{References}

1. Topalian SL, Hodi FS, Brahmer JR, Gettinger SN, Smith DC, McDermott DF, Powderly JD, Carvajal RD, Sosman JA, Atkins MB, Leming PD, Spigel DR, Antonia SJ, Horn L, Drake CG, Pardoll DM, Chen L, Sharfman WH, Anders RA, Taube JM, McMiller TL, Xu H, Korman AJ, Jure-Kunkel M, Agrawal S, McDonald D, Kollia GD, Gupta A, Wigginton JM, Sznol M: Safety, activity, and immune correlates of anti-PD-1 antibody in cancer. N Engl I Med 2012, 366(26):2443-2454.

2. Brahmer JR, Tykodi SS, Chow LQ, Hwu WJ, Topalian SL, Hwu P, Drake CG, Camacho LH, Kauh J, Odunsi K, Pitot HC, Hamid O, Bhatia S, Martins R, Eaton K, Chen S, Salay TM, Alaparthy S, Grosso JF, Korman AJ, Parker SM, Agrawal S, Goldberg SM, Pardoll DM, Gupta A, Wigginton JM: Safety and activity of anti-PD-L1 antibody in patients with advanced cancer. N Engl J Med 2012, 366(26):2455-2465.

3. Beatty GL, Chiorean EG, Fishman MP, Saboury B, Teitelbaum UR, Sun W, Huhn RD, Song W, Li D, Sharp LL, Torigian DA, O'Dwyer PJ, Vonderheide RH: CD40 agonists alter tumor stroma and show efficacy against pancreatic carcinoma in mice and humans. Science 2011, 331(6024):1612-1616.

4. Pages F, Galon J, Dieu-Nosjean MC, Tartour E, Sautes-Fridman C, Fridman WH: Immune infiltration in human tumors: a prognostic factor that should not be ignored. Oncogene 2010, 29(8):1093-1102.

5. Tosolini M, Kirilovsky A, Mlecnik B, Fredriksen T, Mauger S, Bindea G, Berger A, Bruneval P, Fridman WH, Pages F, Galon J: Clinical impact of different classes of infiltrating T cytotoxic and helper cells (Th1, th2, treg, th17) in patients with colorectal cancer. Cancer Res 2011, 71(4):1263-1271.

6. Kisielewicz A, Schaier M, Schmitt E, Hug F, Haensch GM, Meuer S, Zeier M, Sohn C, Steinborn A: A distinct subset of HLA-DR +-regulatory T cells is involved in the induction of preterm labor during pregnancy and in the induction of organ rejection after transplantation. Clin Immunol 2010, 137(2):209-220.

7. Schober L, Radnai D, Schmitt E, Mahnke K, Sohn C, Steinborn A: Term and preterm labor: decreased suppressive activity and changes in composition of the regulatory T-cell pool. Immunol Cell Biol 2012, 90(10):935-944.

8. Manfredi S, Lepage C, Hatem C, Coatmeur O, Faivre J, Bouvier AM: Epidemiology and management of liver metastases from colorectal cancer. Ann Surg 2006, 244(2):254-259.

9. Abdalla EK, Vauthey JN, Ellis LM, Ellis V, Pollock R, Broglio KR, Hess K, Curley SA Recurrence and outcomes following hepatic resection, radiofrequency ablation, and combined resection/ablation for colorectal liver metastases. Ann Surg 2004, 239(6):818-825. discussion 825-7.

10. Adam R, Wicherts DA, de Haas RJ, Ciacio O, Levi F, Paule B, Ducreux M, Azoulay D, Bismuth H, Castaing D: Patients with initially unresectable colorectal liver metastases: is there a possibility of cure? I Clin Oncol 2009, 27(11):1829-1835.

11. Wagner $P$, Koch $M$, Nummer D, Palm $S$, Galindo L, Autenrieth D, Rahbari N, Schmitz-Winnenthal FH, Schirrmacher V, Buchler MW, Beckhove P, Weitz J: Detection and functional analysis of tumor infiltrating T-lymphocytes (TIL) in liver metastases from colorectal cancer. Ann Surg Oncol 2008, 15(8):2310-2317.

12. Mlecnik B, Tosolini M, Kirilovsky A, Berger A, Bindea G, Meatchi T, Bruneval P, Trajanoski Z, Fridman WH, Pages F, Galon J: Histopathologic-based prognostic factors of colorectal cancers are associated with the state of the local immune reaction. J Clin Oncol 2011, 29(6):610-618.

13. Hwang WT, Adams SF, Tahirovic E, Hagemann IS, Coukos G: Prognostic significance of tumor-infiltrating $T$ cells in ovarian cancer: a meta-analysis. Gynecol Oncol 2012, 124(2):192-198.

14. Thompson JM, Gralow JR, Levy R, Miller RA: The optimal application of forward and ninety-degree light scatter in flow cytometry for the gating of mononuclear cells. Cytometry 1985, 6(5):401-406.

15. Jenabian MA, Seddiki N, Yatim A, Carriere M, Hulin A, Younas M, Kok E, Ghadimi A, Routy JP, Tremblay A, Sevigny J, Lelievre JD, Levy Y: Regulatory T cells negatively affect IL-2 production of effector T cells through CD39/ adenosine pathway in HIV infection. PLoS Pathog 2013, 9(4):e1003319.

16. Mandapathil M, Lang S, Gorelik E, Whiteside TL: Increased ectonucleotidase expression and activity in regulatory T cells of patients with head and neck cancer. Clin Cancer Res 2009, 15(20):6348-6357.

17. Zabransky DJ, Nirschl CJ, Durham NM, Park BV, Ceccato CM, Bruno TC, Tam AJ, Getnet D, Drake CG: Phenotypic and functional properties of Helios + regulatory T cells. PLoS One 2012, 7(3):e34547.

18. Krummel MF, Allison JP: CD28 and CTLA-4 have opposing effects on the response of T cells to stimulation. J Exp Med 1995, 182:459-466.

19. Seddiki N, Santner-Nanan B, Martinson J, Zaunders J, Sasson S, Landay A Solomon M, Selby W, Alexander SI, Nanan R, Kelleher A, Fazekas de St Groth B: Expression of interleukin (IL)-2 and IL-7 receptors discriminates between human regulatory and activated T cells. J Exp Med 2006, 203(7):1693-1700.

20. Liu W, Putnam AL, Xu-Yu Z, Szot GL, Lee MR, Zhu S, Gottlieb PA, Kapranov P, Gingeras TR, Fazekas de St Groth B, Clayberger C, Soper DM, Ziegler SF, Bluestone JA: CD127 expression inversely correlates with FoxP3 and suppressive function of human CD4+ T reg cells. J Exp Med 2006, 203(7):1701-1711.

21. Jie HB, Gildener-Leapman N, Li J, Srivastava RM, Gibson SP, Whiteside TL, Ferris RL: Intratumoral regulatory T cells upregulate immunosuppressive molecules in head and neck cancer patients. Br J Cancer 2013, 109(10):2629-2635.

22. Schuler PJ, Schilling B, Harasymczuk M, Hoffmann TK, Johnson J, Lang S, Whiteside TL: Phenotypic and functional characteristics of CD4+ CD39+ FOXP3+ and CD4+ CD39+ FOXP3neg T-cell subsets in cancer patients. Eur J Immunol 2012, 42(7):1876-1885.

23. Camus M, Tosolini M, Mlecnik B, Pages F, Kirilovsky A, Berger A, Costes A, Bindea G, Charoentong P, Bruneval P, Trajanoski Z, Fridman WH, Galon J: Coordination of intratumoral immune reaction and human colorectal cancer recurrence. Cancer Res 2009, 69(6):2685-2693.

24. Zhang L, Conejo-Garcia JR, Katsaros D, Gimotty PA, Massobrio M, Regnani G, Makrigiannakis A, Gray H, Schlienger K, Liebman MN, Rubin SC, Coukos G: Intratumoral T cells, recurrence, and survival in epithelial ovarian cancer. N Engl J Med 2003, 348(3):203-213.

25. Miller JD, van der Most RG, Akondy RS, Glidewell JT, Albott S, Masopust D, Murali-Krishna K, Mahar PL, Edupuganti S, Lalor S, Germon S, Del Rio C, Mulligan MJ, Staprans SI, Altman JD, Feinberg MB, Ahmed R: Human effector and memory CD8+ T cell responses to smallpox and yellow fever vaccines. Immunity 2008, 28(5):710-722. 
26. Hagemann AR, Cadungog M, Hagemann IS, Hammond R, Adams SF, Chu CS, Rubin SC, Zhang L, Addya K, Birrer M, Gimotty PA, Coukos G: Tissue-based immune monitoring II: multiple tumor sites reveal immunologic homogeneity in serous ovarian carcinoma. Cancer Biol Ther 2011, 12(4):367-377.

27. Pedroza-Gonzalez A, Verhoef C, ljzermans JN, Peppelenbosch MP, Kwekkeboom J, Verheij J, Janssen HL, Sprengers D: Activated tumorinfiltrating $\mathrm{CD} 4+$ regulatory $\mathrm{T}$ cells restrain antitumor immunity in patients with primary or metastatic liver cancer. Hepatology 2013, 57(1):183-194.

28. $\mathrm{Ma}$ C, Dong X: Colorectal cancer-derived Foxp3(+) IL-17(+) T cells suppress tumour-specific CD8+ T cells. Scand J Immunol 2011, 74(1):47-51.

29. Lindau D, Gielen P, Kroesen M, Wesseling P, Adema GJ: The immunosuppressive tumour network: myeloid-derived suppressor cells, regulatory T cells and natural killer T cells. Immunology 2013, 138(2):105-115.

30. Ahmadzadeh M, Johnson LA, Heemskerk B, Wunderlich JR, Dudley ME, White DE, Rosenberg SA: Tumor antigen-specific CD8 T cells infiltrating the tumor express high levels of PD-1 and are functionally impaired. Blood 2009, 114(8):1537-1544.

31. Anderson AC: Tim-3, a negative regulator of anti-tumor immunity. Curr Opin Immunol 2012, 24(2):213-216.

32. Fisher DT, Appenheimer MM, Evans SS: The two faces of IL-6 in the tumor microenvironment. Semin Immunol 2014, 26(1):38-47.

33. Yu H, Kortylewski M, Pardoll D: Crosstalk between cancer and immune cells: role of STAT3 in the tumour microenvironment. Nat Rev Immunol 2007, 7(1):41-51.

34. Yu H, Pardoll D, Jove R: STATs in cancer inflammation and immunity: a leading role for STAT3. Nat Rev Cancer 2009, 9(11):798-809.

35. Roederer M: Spectral compensation for flow cytometry: visualization artifacts, limitations, and caveats. Cytometry 2001, 45(3):194-205.

36. Baecher-Allan C, Brown JA, Freeman GJ, Hafler DA: Cd4(+)cd25(high) regulatory cells in human peripheral blood. I Immunol 2001, 167(3):1245-1253.

doi:10.1186/s40425-014-0038-9

Cite this article as: Kovacsovics-Bankowski et al:: Detailed

characterization of tumor infiltrating lymphocytes in two distinct human solid malignancies show phenotypic similarities. Journal for ImmunoTherapy of Cancer 2014 2:38.

\section{Submit your next manuscript to BioMed Central and take full advantage of:}

- Convenient online submission

- Thorough peer review

- No space constraints or color figure charges

- Immediate publication on acceptance

- Inclusion in PubMed, CAS, Scopus and Google Scholar

- Research which is freely available for redistribution 